\title{
NEW METHODS FOR INSURING PSYCHIC HEALTH IN ADOLESCENTS IN THE RESIDENTIAL ENVIRONMENT
}

\author{
Alina Maria Breaz \\ Aurel VlaicU University from Arad, Romania
}

\begin{abstract}
:
Background: Adolescents from placement centers are more likely to develop disharmonious personality structures, due to the multiple risk factors existing in the residential environment: lack of an identification model, absence of attachment, conflicts with other colleagues or staff. That is why it is necessary to intervene in order to maintain the mental balance of adolescents and to create the necessary premises for a harmonious structuring of the personality.

Methods: Worked in the team (psychologist, social worker) for the implementation of an intervention program consisting of 12 sessions of cognitive behavioral psychotherapy and 12 sessions of care counseling, which were held once a week for 3 months. The adolescents included in the study were 40, divided into 4 groups of 10 each for psychotherapy and counseling sessions. At the beginning and at the end of the intervention, a personality questionnaire was applied (Woodworth-Mathews) to highlight the personality traits.

Results: Comparing the answers with the help of the t-Student test revealed significant differences between the personality trait averages in the two assessments, demonstrating that the intervention performed had favorable results in attenuating the marked features and in restoring the mental balance and the mental health of the adolescents.

Conclusions: The combined intervention programs (psychotherapy and counseling) can contribute to the improvement of the mental health of the adolescents in the placement centers and help to structure harmonious personalities of the adolescents in the residential environment.
\end{abstract}

Key words: adolescents, residential environment, psychotherapy, counseling, personality traits 